\title{
Technological Heredity of the Turning Process
}

\author{
Paweł ZMARZKY
}

\begin{abstract}
The paper presents studies aimed at analyzing the influence of the change in feed rate and the cutting speed of the longitudinal turning process on the parameters of roughness, roundness and cylindricity of the machined surface. For selected surfaces, a comprehensive 3D surface topography study was carried out Form Talysurf 1200 PGI contact profilometer by Taylor Hobson. Five different materials were used for the studies: general purpose carbon steel C45, alloy steel S355, cold working tool steel NC6, brass MO58 and aluminum alloy AW-2017A. In addition, Pearson's linear correlation coefficients were calculated in order to quantify the relationship between the analyzed parameters. Based on the results obtained, the analysis of technological heredity of the longitudinal turning process was carried out. It has shown that the technological parameters of the longitudinal turning process have a significant influence on the roughness parameters of the machined surface.
\end{abstract}

Keywords: longitudinal turning; machining parameters; roundness; surface texture, technological heredity

\section{INTRODUCTION}

Despite the intensive development of additive technologies [1], machining, and in particular the process of longitudinal turning, is still the most frequently used form of manufacturing. Many factors influence the surface quality of longitudinally turned workpieces. The most important ones include: technological parameters of the machining process, stereometry of the cutting edge, vibrations resulting from the machining process, machinability of the workpiece, built up edge, elastic and plastic deformation of the tool and workpiece in the machining zone [2-4]. On the other hand, the dominant factors influencing the quality of the turned surface are the complex motion of the cutting tool and workpiece expressed by the feed rate $f_{\mathrm{n}}$ and the cutting speed $v_{\mathrm{c}}$. These parameters should be selected in such a way that the machining is as efficient as possible while maintaining the high quality of the surface layer of the workpiece $[5,6]$. Due to the increasing demands concerning modern manufacturing processes, often conflicting processing conditions must be reconciled. For example, due to the desired high dimension and shape accuracy of workpieces, it is recommended to select low feed rates, which results in a decrease of the machining performance. Excessive increase of a feed rate, in turn, decreases the quality of the machined surface and reduces the service life of the cutting edge. Therefore, a compromise between machining performance and the desired quality of the machined surface should be sought. It should be noted, that the intensive development in the field of surface metrology allows for a more comprehensive analysis of the surface topography of machined surfaces $[7,8]$.

Manufacturers of cutting tools specify the optimal machining parameters at which the satisfactory quality of the machined surface is achieved. However, the proposed machining parameters do not always allow the assumed technological requirements for the workpiece to be reached. This is particularly important in case of the production of important machine parts such as rolling bearings [9]. Other factors that affect the quality of the machining performed, e.g. the condition of the machine or the cutting tool, should be taken into account $[10,11]$.

The feed rate affects the roughness of turned surfaces directly by a kinematic representation of the cutting edge.
This influence is more evident in the case of higher feed rates characteristic of rough turning. On the other hand, the influence of machining speed on surface roughness is mainly related to the lack of occurrence of built up edge during machining and the value of the coefficient of friction between the cutting edge and the workpiece material $[12,13]$.

Due to the importance of the technological parameters of the turning process, there is a need to conduct studies aimed at analyzing the impact of changes in the machining parameters of selected machining processes on the quality of the machined surface and at the same time analyzing the efficiency of the machining process. It should be added that research work has been carried out in order to assess the influence of machining parameters on the condition of the machined surface, however, in most cases only the condition of the surface layer was analyzed by evaluating the parameters of $2 \mathrm{D}$ roughness $[14,15]$. There is no research work that evaluates the quality of the produced elements in a more detailed way, taking into account variable machining parameters, e.g. evaluation of surface roughness, cylindricality or surface waviness. These parameters are extremely important in the case of cylindrical workpieces with a rotary or reciprocating motion. Excessive values of roughness and waviness deviations may cause excessive vibrations and noise of mechanisms $[9,16]$. This has a significant impact on the performance parameters of the finished devices, which is an example of operational heredity.

It should be added that improperly selected parameters of machining may cause errors (defects) of the machined surface. This will influence the subsequent technological operations and, consequently, the condition of the final product. Then we are dealing with inheritance of errors resulting from an improperly conducted technological process. Such a phenomenon is referred to as technological heredity. For the first time, the concept of technological heredity in the context of machining appeared in Russia in the 1980s $[17,18]$. The analysis of technological heredity allows to determine the stage of the technological process of the product at which a given error occurs and the way it is formed during the whole production process. Hereditary information is extremely important because it allows for a better understanding of the process of creating and transferring errors and an introduction of possible 
corrective measures so that the product meets the assumed requirements [19].

Analysis of the longitudinal turning process in terms of technological heredity will allow for assessment of how the tested technological parameters affect the roughness of the machined surface and shape deviations of the tested samples. Thanks to this it will be possible to analyze how the deviations affect further technological processes or the final workpiece. Moreover, metrology studies will allow for the detection of errors resulting from previous technological processes. Such an analysis is particularly important in the case of series production of precision machine parts, as it helps to streamline the production process.

\section{METHODS OF STUDIES}

The studies conducted for the purpose of the article can be divided into 3 main stages. The individual steps of testing procedure are illustrated by the flowchart shown in Fig. 1.

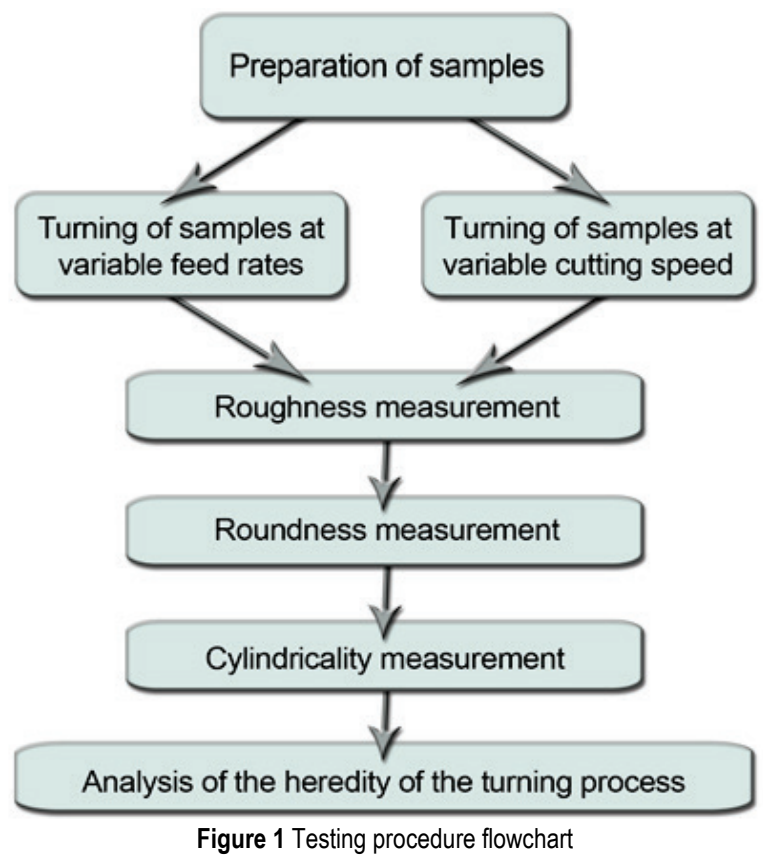

The first stage concerned the turning of prepared samples taking into account the variable feed rates $f_{\mathrm{n}}$ and cutting speeds $v_{\mathrm{c}}$. Five different materials were tested, therefore a total of 10 samples were prepared. The next stage was metrology studies consisting in the measurement of roughness, roundness and cylindricality of machined surfaces. The last stage was an analysis of the technological heredity of the longitudinal turning process. The tests were carried out in the Laboratory of Numerically Controlled Machines and the Laboratory of Computer Measurement of Geometrical Quantities at the Kielce University of Technology.

\subsection{Samples Used for Testing}

Under experimental studies, five different materials were tested, i.e. general-purpose non-alloy steel C45, cold working tool steel NC6 (145Cr6), alloy steel S355, brass M058 $\left(\mathrm{CuZn}_{40} \mathrm{~Pb}_{2}\right)$ and aluminum alloy AW-2017A
$\left(\mathrm{AlCu}_{4} \mathrm{MgSi}(\mathrm{A})\right)$. To carry out the studies, 10 samples were prepared in cylindrical form ( 5 for the analysis of feed rate $f_{\mathrm{n}}$ and 5 for the analysis of cutting speed $v_{\mathrm{c}}$ ). On each sample, 6 surfaces were prepared for which the feed rate or cutting speed were analyzed. Therefore, 6 different feed rates and 6 different cutting speeds were tested for each material. Fig. 2 shows the samples used for testing.

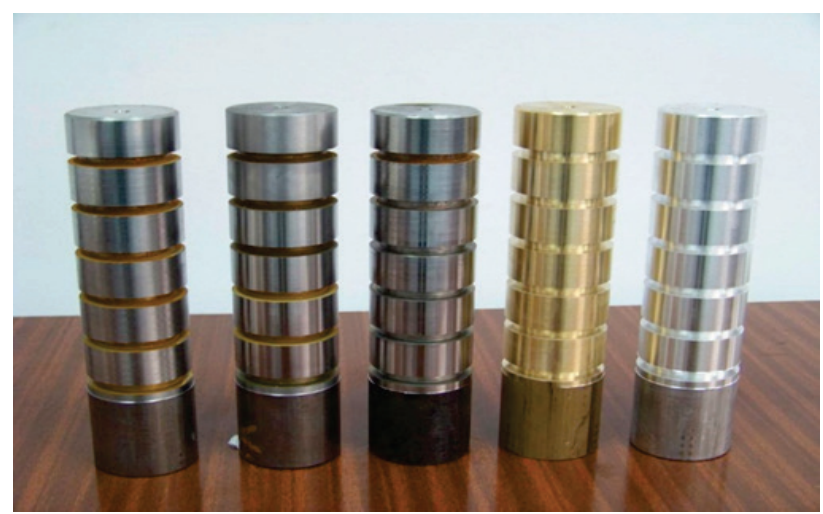

Figure 2 Samples used for testing, from the left: steel C45, steel NC6, steel S355, brass M058, aluminum alloy AW-2017A

The materials used for the manufacture of the samples were selected because of their high popularity in industrial applications. Moreover, their various material properties allow for a broader analysis of the influence of technological parameters of the turning process on the condition of the machined surface. Tab. 1 presents selected mechanical properties of examined materials.

Table 1 Selected mechanical properties of the analyzed materials [20-24]

\begin{tabular}{|c|c|c|c|c|}
\hline Material & $\begin{array}{c}\text { Tensile } \\
\text { strength } R_{\mathrm{m}} \\
/ \mathrm{MPa}\end{array}$ & $\begin{array}{c}\text { Yield } \\
\text { strength } R_{\mathrm{e}} / \\
\mathrm{MPa}\end{array}$ & $\begin{array}{l}\text { Young's } \\
\text { Modulus } E \\
/ \mathrm{GPa} \\
\end{array}$ & $\begin{array}{c}\text { Hardness } \\
\text { after } \\
\text { softening }\end{array}$ \\
\hline $\mathrm{C} 45$ & $\min .580$ & $\min .305$ & 198 & $229 \mathrm{HB}$ \\
\hline $\begin{array}{c}\text { NC6 } \\
(145 \mathrm{Cr} 6)\end{array}$ & $\min .620$ & $\min .248$ & 210 & $248 \mathrm{HB}$ \\
\hline S355 & $\min .490$ & $\min .345$ & 210 & $220 \mathrm{HB}$ \\
\hline MO58 & $\min .360$ & $\min .150$ & 96 & $120 \mathrm{HB}$ \\
\hline AW-2017A & $\min .425$ & $\min .290$ & 72.5 & $110 \mathrm{HB}$ \\
\hline
\end{tabular}

\subsection{Machining-Longitudinal Turning}

Previously prepared samples (see Fig. 2) were subject to the process of longitudinal turning using the Cyclone TU 150P numerically controlled lathe by Denford Machine Tools Ltd. Sandvik Coromant's cutting inserts designed for finishing were used for the process of turning. These are inserts with a specially profiled rake face which ensures proper chip flow and breakage. Pursuant to the recommendations of the cutting inserts' manufacturer, one type of inserts was used for machining steel and brass (DCGT 11 T3 04-UM 1125), and another one for aluminum alloy (DCGX 11 T3 04-AL H10). Tab. 2 shows the basic parameters of the inserts used.

The inserts had the same geometry and different coatings. Therefore, depending on the type of machined material, different cutting speed ranges were analyzed, while the feed rates $f_{\mathrm{n}}$ were the same for all tested materials, i.e. $0.04 \mathrm{~mm}, 0.08 \mathrm{~mm}, 0.12 \mathrm{~mm}, 0.16 \mathrm{~mm}, 0.2 \mathrm{~mm}, 0.24$ $\mathrm{mm}$. The first stage of turning process was turning of the previously made samples at a variable feed rate $f_{\mathrm{n}}$, while the depth of cut and cutting speed were constant $\left(a_{\mathrm{p}}=0.15\right.$ $\mathrm{mm}, v_{\mathrm{c}}=205 \mathrm{~m} / \mathrm{min}$ ). The second stage was to analyze the 
cutting speed $v_{\mathrm{c}}$, with a constant feed rate $f_{\mathrm{n}}=0.16 \mathrm{~mm}$ and the cutting depth $a_{\mathrm{p}}=0.15 \mathrm{~mm}$. The analyzed values of machining parameters depending on the material are presented in Tab. 3.

Table 2 Parameters of the inserts used [25]

\begin{tabular}{|c|c|c|}
\hline Parameter & & Value \\
\hline Apex angle & & $55^{\circ}$ \\
\hline Clearance angle & & $7^{\circ}$ \\
\hline Corner radius $R_{\mathrm{e}}$ & & $.397 \mathrm{~mm}$ \\
\hline \multirow{2}{*}{ Coverage } & 04-UM 1125 & $\mathrm{PVD}(\mathrm{Ti}, \mathrm{Al}) \mathrm{N}+(\mathrm{Al}, \mathrm{Cr}) 2 \mathrm{O} 3$ \\
\hline & 04-AL H10 & none \\
\hline
\end{tabular}

Table 3 Summary of the tested cutting speeds for the tested materials

\begin{tabular}{|c|c|c|c|c|c|c|}
\hline Material & \multicolumn{7}{|c|}{ Cutting speed $v_{\mathrm{c}} / \mathrm{m} / \mathrm{min}$} \\
\hline C45 & 100 & 150 & 200 & 250 & 300 & 350 \\
\hline NC6 & 100 & 150 & 200 & 250 & 300 & 350 \\
\hline ST355 & 100 & 150 & 200 & 250 & 300 & 350 \\
\hline MO58 & 50 & 100 & 200 & 300 & 400 & 500 \\
\hline AW-2017A & 250 & 350 & 450 & 550 & 650 & 750 \\
\hline
\end{tabular}

\subsection{Metrology Studies}

Metrology studies have been divided into two main parts. The first stage of the studies included measurement and analysis of roughness of turned surfaces. The measurement was carried out with the use of the stylus profilometer TOPO 01 by IOS. Four basic parameters were used to assess the roughness of the machined surface: $R a$, $R t, R_{\mathrm{sk}}, R_{\mathrm{ku}}$. For the purpose of averaging the measurement results, each surface was measured 10 times and then the mean value from the obtained results was determined. Moreover, 3D surface topographies were comprehensively analyzed for selected samples using the Talysurf PGI 1230 measuring system by Taylor Hobson. A surface with dimensions of $0.35 \times 0.35 \mathrm{~mm}$ was analyzed. The sampling interval was $\Delta X=0.05 \mu \mathrm{m}, \Delta Y=10 \mu \mathrm{m}$. The number of repetitions was 125 . The cut-off value was $0.25 \mathrm{~mm}$. The surface topography was removed with a third degree polynomial.

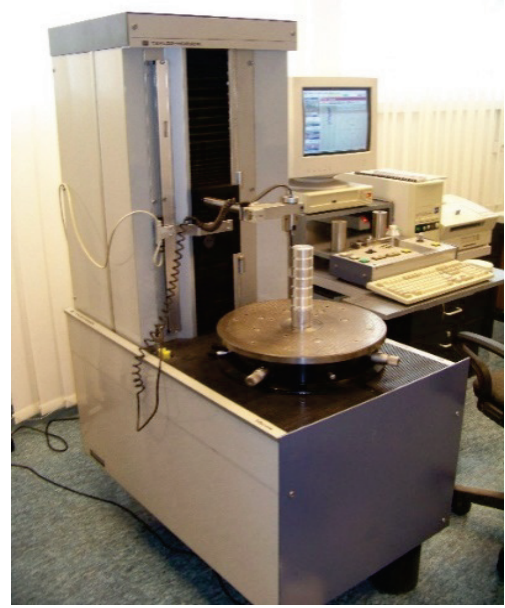

Figure 3 Talycenta measuring device

The second stage of the studies consisted in the analysis of roundness and cylindricity profiles using the Talycenta measurement system by Taylor Hobson. This measuring device uses a radius change method with the rotary table. In order to increase the measurement accuracy, the structure together with the software of this system was modified at the Kielce University of
Technology [26]. Fig. 3 shows the Talycenta measuring device with test sample made of aluminum alloy AW2017A on the measuring table.

The roundness was analyzed in the range of 2-15 undulation per revolution. Filtration of the measured profiles was carried out using a Gaussian filter. The deviation of roundness $R O N t$ was determined on the basis of the mean circle LC. Moreover, this measuring system was used to determine the cylindricity deviation CYLt. This deviation is interpreted as the sum of the highest positive $(C Y L p)$ and negative absolute value $(C Y L v)$ of the cylindrical deviation, which is measured in relation to the associated cylinder determined by the least squares method.

\section{SUMMARY AND ANALYSIS OF RESULTS}

The overall results of the studies are presented in the tables. Tab. 4 shows the results of metrology measurements for variable feed rate $f_{\mathrm{n}}$, while Tab. 5 shows the results for variable cutting speed $v_{\mathrm{c}}$.

Table 4 Summary of results for samples machined at variable feed rate $f_{n}$

\begin{tabular}{|c|c|c|c|c|c|c|c|}
\hline \multirow{2}{*}{ 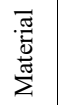 } & \multirow{2}{*}{ Parameters } & \multicolumn{6}{|c|}{ Feed rate $f_{\mathrm{n}} / \mathrm{mm}$} \\
\hline & & 0.04 & 0.08 & 0.12 & 0.16 & 0.2 & 0.24 \\
\hline \multirow{6}{*}{ 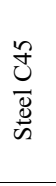 } & $R a / \mu \mathrm{m}$ & 1.79 & 1.82 & 2.19 & 2.65 & 3.21 & 4.28 \\
\hline & $R t / \mu \mathrm{m}$ & 9.99 & 10.63 & 12.03 & 13.96 & 15.87 & 20.03 \\
\hline & $R_{\mathrm{sk}}$ & 0.38 & 0.15 & -0.07 & -0.03 & 0.26 & 0.43 \\
\hline & $R_{\mathrm{ku}}$ & 2.33 & 2.36 & 2.16 & 2.14 & 2.02 & 2.07 \\
\hline & $R O N t / \mu \mathrm{m}$ & 3.49 & 2.77 & 7.43 & 3.65 & 3.96 & 2.79 \\
\hline & $C Y L t / \mu \mathrm{m}$ & 16.6 & 17.1 & 16.7 & 10.7 & 16.6 & 17.9 \\
\hline \multirow{6}{*}{$\begin{array}{l}0 \\
\circlearrowright \\
\bar{\Xi} \\
\frac{\Phi}{\omega}\end{array}$} & $R a / \mu \mathrm{m}$ & 1.68 & 1.63 & 1.57 & 2.09 & 2.71 & 3.64 \\
\hline & $R t / \mu \mathrm{m}$ & 10.1 & 10.75 & 9.92 & 8.43 & 10.56 & 15.93 \\
\hline & $R_{\mathrm{sk}}$ & 0.09 & -0.02 & 0.37 & 0.43 & 0.33 & 0.59 \\
\hline & $R_{\mathrm{ku}}$ & 2.38 & 2.64 & 2.42 & 1.78 & 1.77 & 2.34 \\
\hline & $R O N t / \mu \mathrm{m}$ & 18.6 & 15.3 & 13.5 & 14.2 & 14.3 & 16.9 \\
\hline & $C Y L t / \mu \mathrm{m}$ & 23.1 & 20.5 & 18.6 & 21.5 & 23 & 33.4 \\
\hline \multirow{6}{*}{$\begin{array}{l}n \\
\tilde{n} \\
\tilde{\infty} \\
\bar{\Xi} \\
\text { in }\end{array}$} & $R a / \mu \mathrm{m}$ & 1.85 & 2.02 & 2.45 & 2.62 & 3.18 & 4.24 \\
\hline & $R t / \mu \mathrm{m}$ & 9.81 & 11.89 & 13.33 & 14.64 & 15.78 & 19.06 \\
\hline & $R_{\mathrm{sk}}$ & 0.02 & 0.07 & -0.07 & 0.19 & 0.43 & 0.48 \\
\hline & $R_{\mathrm{ku}}$ & 2.11 & 2.29 & 2.13 & 2.27 & 2.06 & 2.06 \\
\hline & $R O N t / \mu \mathrm{m}$ & 11.23 & 12.15 & 14 & 13.5 & 11.5 & 8.83 \\
\hline & $C Y L t / \mu \mathrm{m}$ & 22.19 & 23.29 & 25.9 & 27.4 & 30.8 & 26.2 \\
\hline \multirow{6}{*}{ 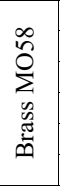 } & $R a / \mu \mathrm{m}$ & 0.68 & 0.82 & 1.02 & 1.48 & 2.85 & 4.3 \\
\hline & $R t / \mu \mathrm{m}$ & 6.59 & 6.67 & 9.22 & 11.17 & 13.67 & 19.79 \\
\hline & $R_{\mathrm{sk}}$ & -0.45 & -0.69 & -0.47 & 0.64 & 0.53 & 0.55 \\
\hline & $R_{\mathrm{ku}}$ & 3.28 & 3.59 & 3.76 & 3.18 & 2.09 & 2.12 \\
\hline & $R O N t / \mu \mathrm{m}$ & 4.88 & 4.14 & 3.72 & 2.78 & 4.45 & 3.25 \\
\hline & $C Y L t / \mu \mathrm{m}$ & 8.07 & 6.83 & 8.06 & 11.5 & 12.9 & 16.7 \\
\hline \multirow{6}{*}{ 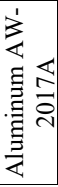 } & $R a / \mu \mathrm{m}$ & 0.38 & 0.52 & 0.99 & 1.81 & 2.88 & 4.19 \\
\hline & $R t / \mu \mathrm{m}$ & 2.66 & 3.42 & 4.87 & 7.6 & 11.51 & 16.41 \\
\hline & $R_{\mathrm{sk}}$ & -0.13 & -0.15 & 0.45 & 0.55 & 0.59 & 0.6 \\
\hline & $R_{\mathrm{ku}}$ & 2.69 & 2.43 & 2.1 & 1.99 & 2.02 & 2.06 \\
\hline & $R O N t / \mu \mathrm{m}$ & 6.46 & 4.86 & 8.86 & 5.18 & 4.57 & 4.51 \\
\hline & CYLt / $\mu \mathrm{m}$ & 7.79 & 14.9 & 16.4 & 9.24 & 11.9 & 19.00 \\
\hline
\end{tabular}

When analyzing the results as a whole, it can be concluded that the lowest roughness values described by $R a$ parameter were obtained for samples made of brass $(R a=0.68 \mu \mathrm{m})$ and aluminum alloy $(R a=0.38 \mu \mathrm{m})$, taking into account the lowest feed rate of $f_{\mathrm{n}}=0.04 \mathrm{~mm}$ (see Tab. 4). These are the values of roughness parameters, which are obtained during traditional grinding machining. The greatest values of the parameter determining the arithmetical mean deviation of the roughness profile were obtained for a sample made of C45 steel $(R a=5.97 \mu \mathrm{m})$. This sample was turned using the following machining parameters: $\left(f_{\mathrm{n}}=0.2 \mathrm{~mm}, a_{\mathrm{p}}=0.15 \mathrm{~mm}, v_{\mathrm{c}}=100 \mathrm{~m} / \mathrm{min}\right)$. 
Similar conclusions can be drawn by considering the values of parameter $R t$. On the other hand, when analyzing the parameter determining the asymmetries of the roughness profile $R_{\mathrm{sk}}$, it can be stated that positive values, close to zero, were obtained in most cases. This means that the analyzed profiles are more symmetrical. A positive value of skewness also means surfaces with a low coefficient of friction, which is particularly desirable for surfaces performing a reciprocating motion [27]. On the other hand, when analyzing the value of $R_{\mathrm{ku}}$ parameter, which is defined as the slope coefficient of the roughness profile, it can be stated that for almost all the obtained samples $R_{\mathrm{ku}}<3$. The exception is a brass sample which was turned with the use of variable feed rates (see Tab. 4). Values of $R_{\mathrm{ku}}$ less than 3 denote surfaces with more rounded spikes, which have a lower coefficient of friction (see Fig. 5). Such a surface is characteristic of turning where the cutting edge with a defined corner radius forms spikes with a rounded surface. Fig. 4 shows an example of a topography of the measured surface for a sample made of C45 steel, taking into account the following machining parameters: $f_{\mathrm{n}}=0.08 \mathrm{~mm}, v_{\mathrm{c}}=205 \mathrm{~m} / \mathrm{min}, a_{\mathrm{p}}=0.15 \mathrm{~mm}$.

\begin{tabular}{|c|c|c|c|c|c|c|c|}
\hline \multirow{2}{*}{ 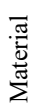 } & \multirow{2}{*}{ Parameters } & \multicolumn{6}{|c|}{ Cutting speed $v_{\mathrm{c}} / \mathrm{m} / \mathrm{min}$} \\
\hline & & 100 & 150 & 200 & 250 & 300 & 350 \\
\hline \multirow{6}{*}{ 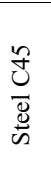 } & $R a / \mu \mathrm{m}$ & 5.87 & 3.34 & 2.58 & 2.55 & 2.7 & 2.73 \\
\hline & $R t / \mu \mathrm{m}$ & 29.81 & 17.16 & 11.91 & 11.56 & 11.29 & 11.19 \\
\hline & $R_{\mathrm{sk}}$ & 0.28 & 0.67 & 0.74 & 0.53 & 0.36 & 0.37 \\
\hline & $R_{\mathrm{ku}}$ & 2.08 & 2.45 & 2.38 & 2.22 & 1.97 & 1.93 \\
\hline & $R O N t / \mu \mathrm{m}$ & 7.06 & 7.09 & 7.71 & 7.2 & 4.52 & 4.13 \\
\hline & $C Y L t / \mu \mathrm{m}$ & 31.9 & 20.2 & 18.1 & 22.7 & 20 & 27.5 \\
\hline \multirow{6}{*}{ 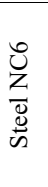 } & $R a / \mu \mathrm{m}$ & 2.62 & 2.65 & 2.66 & 2.65 & 2.68 & 2.66 \\
\hline & $R t / \mu \mathrm{m}$ & 12.01 & 11.72 & 11.75 & 11.78 & 11.63 & 11.75 \\
\hline & $R_{\mathrm{sk}}$ & 0.28 & 0.22 & 0.23 & 0.28 & 0.27 & 0.27 \\
\hline & $R_{\mathrm{ku}}$ & 2.18 & 2.01 & 2.00 & 2.04 & 2.02 & 2.04 \\
\hline & $R O N t / \mu \mathrm{m}$ & 5.12 & 5.85 & 7.12 & 6.22 & 4.3 & 4.14 \\
\hline & $C Y L t / \mu \mathrm{m}$ & 21.15 & 18.23 & 19.55 & 17.23 & 19.27 & 18.4 \\
\hline \multirow{6}{*}{ 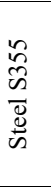 } & $R a / \mu \mathrm{m}$ & 3.63 & 2.75 & 2.52 & 2.52 & 2.62 & 2.68 \\
\hline & $R t / \mu \mathrm{m}$ & 21.38 & 14.67 & 12.76 & 12.78 & 12.22 & 13.16 \\
\hline & $R_{\mathrm{sk}}$ & 0.35 & 0.77 & 0.59 & 0.33 & 0.26 & 0.29 \\
\hline & $R_{\mathrm{ku}}$ & 2.46 & 2.59 & 2.39 & 2.25 & 2.17 & 2.18 \\
\hline & $R O N t / \mu \mathrm{m}$ & 4.98 & 5.1 & 4.22 & 2.12 & 2.48 & 3.16 \\
\hline & $C Y L t / \mu \mathrm{m}$ & 14.7 & 23.6 & 11.3 & 20.3 & 32.9 & 44.7 \\
\hline \multirow{2}{*}{ 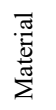 } & \multirow{2}{*}{ Parameters } & \multicolumn{6}{|c|}{ Cutting speed $v_{\mathrm{c}} / \mathrm{m} / \mathrm{min}$} \\
\hline & & 50 & 100 & 200 & 300 & 400 & 500 \\
\hline \multirow{6}{*}{ 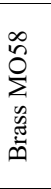 } & $R a / \mu \mathrm{m}$ & 3.53 & 3.01 & 2.5 & 2.59 & 2.81 & 2.97 \\
\hline & $R t / \mu \mathrm{m}$ & 21.8 & 17.72 & 14.31 & 14.38 & 14.61 & 15.46 \\
\hline & $R_{\mathrm{sk}}$ & 0.13 & 0.17 & -0.17 & -0.07 & -0.08 & 0.01 \\
\hline & $R_{\mathrm{ku}}$ & 2.28 & 2.21 & 2.17 & 2.07 & 2.01 & 1.98 \\
\hline & $R O N t / \mu \mathrm{m}$ & 7.44 & 8.2 & 5.3 & 4.71 & 6.42 & 5.14 \\
\hline & $C Y L t / \mu \mathrm{m}$ & 14.3 & 27.3 & 43.3 & 24.9 & 12.9 & 18.3 \\
\hline \multirow{2}{*}{ 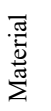 } & \multirow{2}{*}{ Parameters } & \multicolumn{6}{|c|}{ Cutting speed $v_{\mathrm{c}} / \mathrm{m} / \mathrm{min}$} \\
\hline & & 250 & 350 & 450 & 550 & 650 & 750 \\
\hline \multirow{6}{*}{ 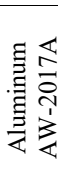 } & $R a / \mu \mathrm{m}$ & 2.94 & 2.96 & 2.93 & 2.93 & 2.91 & 1.71 \\
\hline & $R t / \mu \mathrm{m}$ & 12.17 & 11.99 & 12.24 & 12.09 & 11.83 & 9.99 \\
\hline & $R_{\mathrm{sk}}$ & 0.59 & 0.58 & 0.55 & 0.59 & 0.50 & 0.49 \\
\hline & \begin{tabular}{|l|}
$\mathrm{sk}$ \\
$\mathrm{ku}$
\end{tabular} & 2.04 & 2.01 & 2.00 & 1.99 & 1.99 & 2.33 \\
\hline & $R O N t / \mu \mathrm{m}$ & 5.38 & 5.27 & 3.25 & 3.46 & 4.45 & 4.81 \\
\hline & $C Y L t / \mu \mathrm{m}$ & 6.8 & 6.82 & 25.4 & 13.9 & 9.54 & 23.7 \\
\hline
\end{tabular}

When analyzing the shape deviations of the tested samples, it can be stated that the lowest values of roundness deviations $R O N t$ were obtained for a sample made of $\mathrm{C} 45$ steel, which was turned at a constant cutting speed, and at variable feed rate (see Tab. 4). Moreover, it can be noted that for samples made at variable cutting speeds, roundness deviation values were greater than for samples turned at variable feed rates (see Tab. 5). It is possible to draw the initial conclusion that the cutting speed has a greater influence on the values of the roundness deviations.

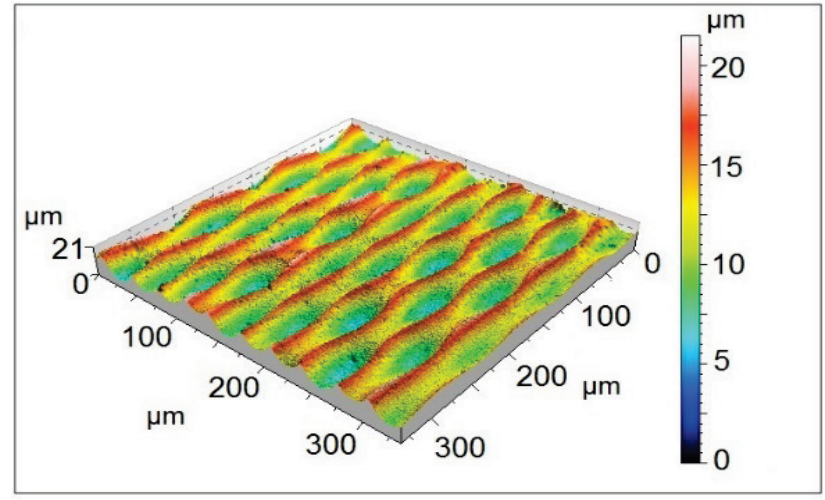

Figure 4 Isometric view of the surface of the sample made of C45 steel

By analyzing the cylindrical surfaces in more detail through evaluation of the cylindricity deviation CYLt, similar conclusions can be drawn as in the analysis of roundness deviation $R O N t$. In this case, higher values of cylindricity deviations CYLt were obtained for samples turned with different cutting speeds $v_{\mathrm{n}}$. An exception is a sample made of aluminum alloy, where the values of CYLt were the lowest.

In order to carry out a more detailed analysis of the effect of the change in feed rate $f_{\mathrm{n}}$ and cutting speed $v_{\mathrm{c}}$ on shape accuracy of turned surfaces, the results are presented in the form of a graph of selected parameters of roughness, roundness and cylindricity in the function of feed rates $f_{\mathrm{n}}$ (see chapter 3.1) and the value of cutting speed $v_{\mathrm{c}}$ (see chapter 3.2). In order to facilitate the interpretation of the obtained dependencies, the trend lines were marked on the graphs. These lines were matched to the results obtained using the least squares method. Moreover, for the purpose of quantitative assessment of the relation between the values of cutting parameters and the parameters of roughness, roundness and cylindricity, Pearson's linear correlation coefficients were calculated for these values. The correlation between the analyzed parameters was then evaluated.

\subsection{Analysis of the Impact of Feed Rate $f_{n}$}

When analyzing the graphs presented in Fig. 5 and Fig. 6 , it can be unequivocally stated that an increase in the feed rate $f_{\mathrm{n}}$ of the longitudinal turning process results in an increase in the roughness value for all materials analyzed. This increase was most evident for the sample made of aluminum alloy AW-2017A (green trend line in Fig. 5 and Fig. 6). On the other hand, for a sample made of tool steel NC6, it can be noticed that the initial increase in feed rate causes a slight decrease in the roughness parameter $R a$. However, after exceeding the feed rate $f_{\mathrm{n}}=0.16 \mathrm{~mm}$, the parameter $R a$ increases rapidly (see Fig. 5). A similar phenomenon was observed for parameter Rt. It should be noted that in case of longitudinal turning of workpieces using low feed rates, there is an increase in vibration amplitude, an increase in the non-removable machining 
allowance and an increase in the hardening of the machined surface, and thus excessive cutting edge wear, which at a later stage of machining may contribute to an increase in the roughness value. Therefore, despite the fact that an increase in feed rate causes an increase in the values of the roughness parameters $R a$ and $R t$, it is not recommended to use too low feed rates. An exception may be a technological process in which the critical criterion is to obtain the lowest roughness values during turning operations. In this case, the lowest possible feed rates should be used.

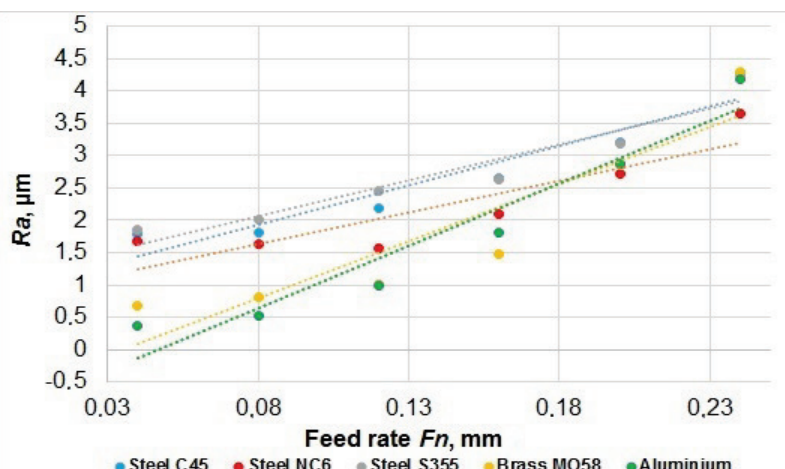

Figure $\mathbf{5}$ Graph showing dependency of the value of $R$ a parameter on the value of feed rate $f_{n}$

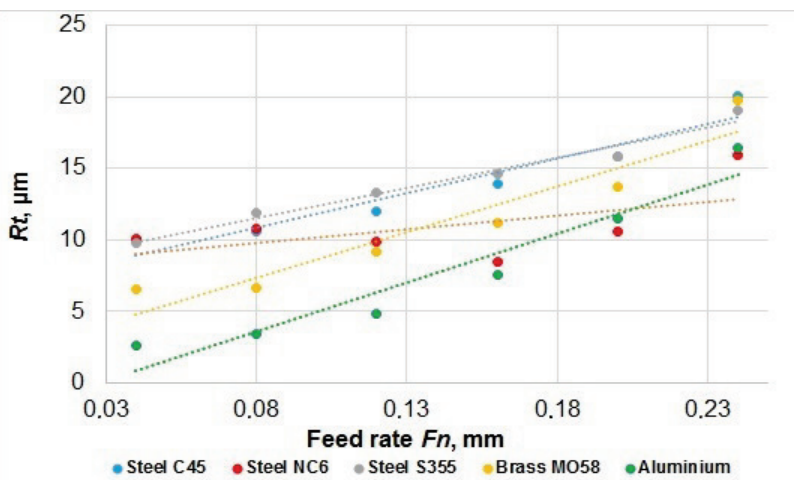

Figure 6 Graph showing dependency of the value of $R t$ parameter on the value of feed rate $f_{n}$

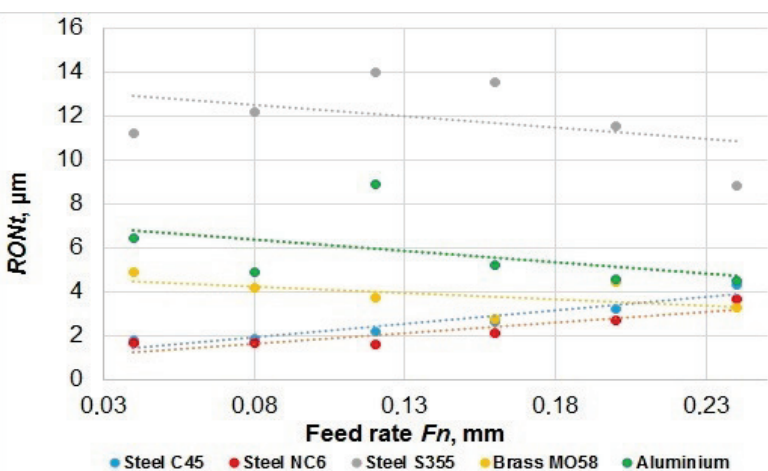

Figure 7 Graph showing dependency of the value of roundness deviation RONt on the value of feed rate $f_{n}$

When analyzing the results presented in the graph in Fig. 7, it can be noticed that an increase in feed rate $f_{\mathrm{n}}$ causes a slight increase in roundness deviations for samples made of C45 and NC6 steel. On the other hand, trend lines determined for samples made of S355 steel, MO58 bronze and AW-2017A aluminum show a slight decrease in the analyzed deviations. The values of roundness deviations
RONt measured for S355 low alloy steel significantly exceed the values measured for other materials. Moreover, when carrying out the harmonic analysis of roundness profiles, the second harmonic component was dominant in most cases. This indicates the oval shape of the roundness profile. This may be due, among other things, to circular oscillation caused by incorrect fixing of the workpiece in the holder of the machine tool. It should be added that the deviation of roundness was tested only in one cross-section of the machined cylindrical surface. Therefore, in order to analyze the cylindrical shape of the tested samples in more detail, the cylindrical profiles were studied, and the results are presented in Tab. 5 and in the graph in Fig. 8.

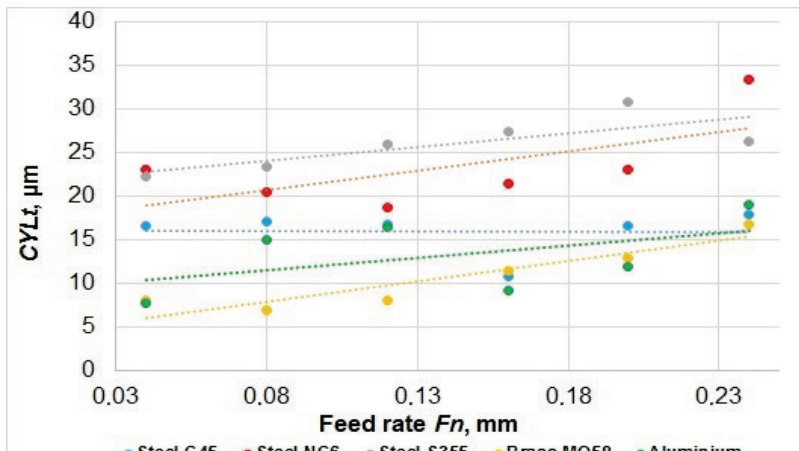

Figure 8 Graph showing dependency of the value of cylindrical shape deviation CYLt on the value of feed rate $f_{n}$

When analyzing the dependence of the values of feed rate $f_{\mathrm{n}}$ of longitudinal turning on the values of the cylindricity deviation CYLt, more clear conclusions can be drawn. In this case, a moderate increase in cylindricality deviation was noted for all materials analyzed due to the increase in feed rate $f_{\mathrm{n}}$. Only the cylindricality deviation of the C45 steel sample remains constant (see blue trend line in Fig. 8). When analyzing the shape of cylindrical surfaces, it can be stated that in this case, a conical shape was obtained for most of the turned surfaces at variable feed rates. An example of a cylindrical profile obtained for a turned aluminum sample, taking into account the following machining parameters: $f_{\mathrm{n}}=0.12 \mathrm{~mm}, v_{\mathrm{c}}=200$ $\mathrm{m} / \mathrm{min}, a_{\mathrm{p}}=0.15 \mathrm{~mm}$ (Tab. 4) was presented in Fig. 9.

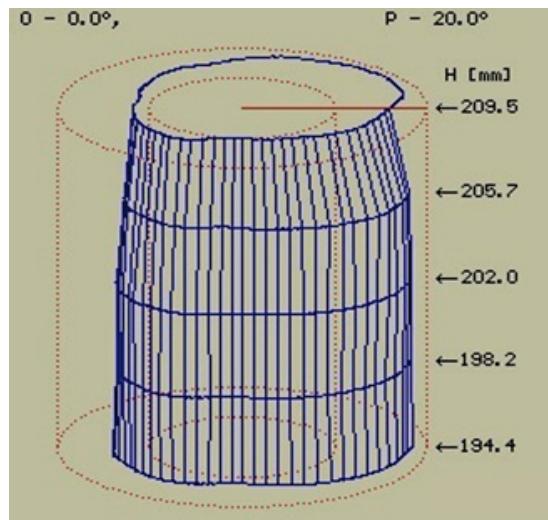

Figure 9 Example of cylindrical profile measured with Talycent's instrument.

In order to quantify the relationship between the feed rates for the materials tested and the selected parameters describing the quality of the machined surface, Pearson's linear correlation coefficients were calculated for these values and then the correlation was assessed according to 
I. P. Guilford [14]. Tab. 6 shows the Pearson's coefficients calculated for the results shown in Tab. 4.

When analyzing the results presented in Tab. 6, it can be concluded that the highest values of Pearson's coefficients were obtained for the roughness parameters. For all tested materials there is a "perfect" correlation between the tested feed rates and the obtained values of roughness parameters. The only exception is a sample made of tool steel NC6, where there is very strong correlation for parameter $R a(r=0.89)$ and moderate correlation for parameter Rt $(r=0.56)$. This means that feed rates significantly affect the condition of the surface texture. On the other hand, significantly lower values of Pearson's coefficients were obtained for the roundness deviation RONt and cylindricality deviation CYNt. For a sample made of $\mathrm{C} 45$ steel, there is practically no relation between the feed rates and the values of the measured deviations in roundness and cylindricality. This is confirmed by the graphs shown in Fig. 7 and Fig. 8, where with the increase in the turning feed rate, the values of roundness deviation $R O N t$ and cylindricality deviation CYLt measured for C45 steel oscillated around a constant value. For other analyzed materials there was a weak, moderate and strong correlation. Only for the brass sample there was almost perfect correlation between the feed rate and the measured cylindrical deviation $(r=0.92)$.

Table 6 Values of Pearson's linear correlation coefficients $(r)$

Table 6 Values of Pearson's linear correlation coefficients $(r)$
\begin{tabular}{|c|c|c|c|c|}
\hline & $R a$ & $R t$ & $R O N t$ & $C Y L t$ \\
\hline C45 & 0.95 & 0.96 & -0.11 & -0.02 \\
\hline NC6 & 0.89 & 0.56 & -0.30 & 0.64 \\
\hline S355 & 0.95 & 0.99 & -0.42 & 0.77 \\
\hline MO58 & 0.92 & 0.95 & -0.56 & 0.92 \\
\hline AW-2017A & 0.96 & 0.96 & -0.45 & 0.49 \\
\hline
\end{tabular}

\subsection{Analysis of the Influence of the Cutting Speed $v_{c}$}

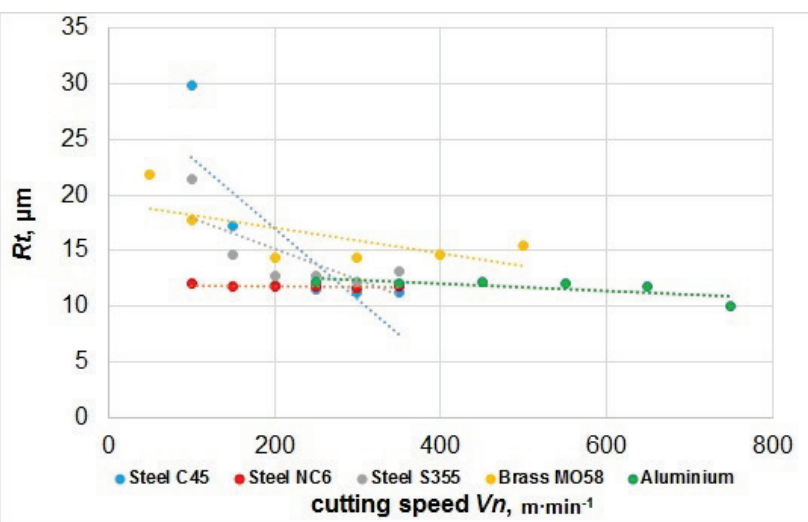

Figure 10 Graph showing dependency of the value of $R a$ parameter on the value of the cutting speed $v_{c}$

When analyzing the effect of the change in the cutting speed of the longitudinal turning process $v_{\mathrm{c}}$ on the roughness of the machined surface, it is not possible to draw as clear conclusions as in the analysis of the influence of feed rate $f_{\mathrm{n}}$ (see chapter 3.1).

For samples made of tool steel NC6 and aluminum AW-2017A, the values of the analyzed roughness parameters ( $R a$ and $R t$ ) practically did not change as a result of increased cutting speed. However, for the rest of the studied materials, the increase in cutting speed caused the initial sharp decrease in the value of the parameter determining the arithmetical mean deviation of the roughness profile $(R a)$ as well as the total height of the roughness profile $(R t)$. The largest decrease was recorded for a sample made of $\mathrm{C} 45$ steel. This was caused by a very high roughness value for the surface turned at the lowest cutting speed $v_{\mathrm{c}}=100 \mathrm{~m} / \mathrm{min}$. However, after exceeding the machining of $v_{\mathrm{c}}=200 \mathrm{~m} / \mathrm{min}$, the values of the roughness parameters stabilized and remained at the same level (see Fig. 10 and Fig. 11). It can therefore be concluded that machining at excessively low cutting speeds is not advisable, as this is associated with an increase in the roughness of turned surfaces.

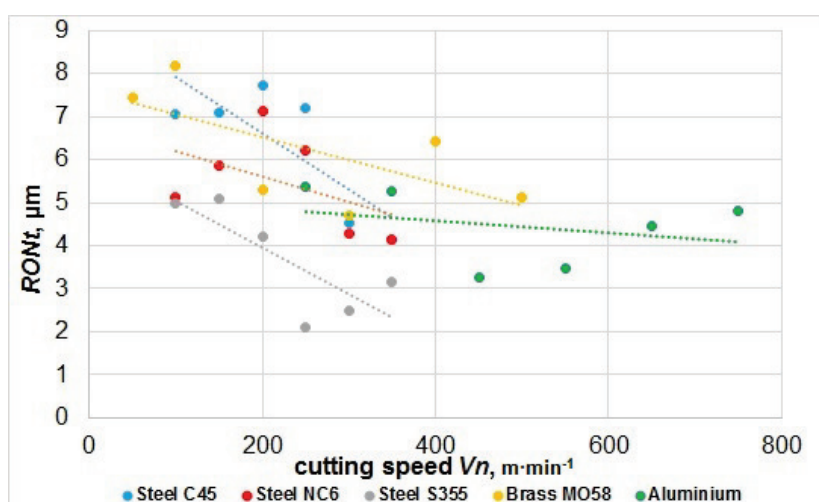

Figure 11 Graph showing dependency of the value of $R t$ parameter on the value of the cutting speed $v_{c}$

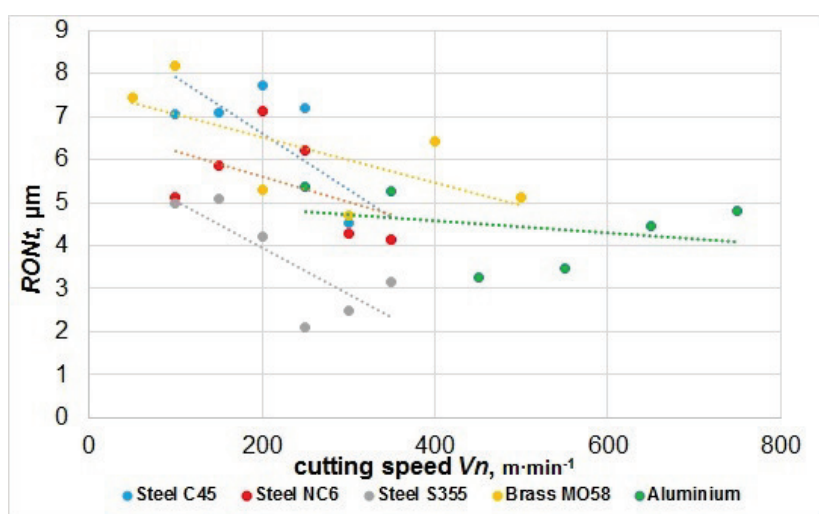

Figure 12 Graph showing dependency of the value of $R t$ parameter on the value of the cutting speed $v_{c}$

Taking into account the results obtained from the roundness measurements, we can see that, depending on the type of the material studied, despite maintaining the same machining parameters, the discrepancies between the analyzed RONt roundness deviations are significant. On the other hand, for all the studied materials a certain dependency can be seen. Analyzing the trend lines shown in the graph in Fig. 12, it can be stated that with the increase in the cutting speed $v_{\mathrm{c}}$, the values of roundness deviations show a decreasing tendency. However, after exceeding certain values of the cutting speed, the values of roundness deviations gradually increase. This is particularly noticeable for samples made of AW-2017A aluminum and S355 steel. The harmonic analysis of roundness profiles measured for samples turned at variable cutting speeds shows that the second and third harmonic components were dominant. It is known that the increase in cutting speed $v_{\mathrm{c}}$ is related to the increase in rotational speed $n$ of the turned workpiece. Then the centrifugal forces acting on the lathe 
chuck are greater, which may result in surface deformation and creation of the so-called triangularity.

It is difficult to draw unambiguous conclusions when analyzing the results presented in Fig. 13. We can see here that with the increase in the cutting speed $v_{\mathrm{c}}$, the values of cylindrical deviations CYLt change significantly in an irregular manner. The greatest discrepancy was noted for samples made of S355 steel and MO58 brass. For these materials, the cylindricality deviation due to the increase in cutting speed once increased and once decreased. On the other hand, for a sample made of C45 steel, after the initial sharp decrease in the value of cylindricality deviation, a moderate increase occurs with the increase in the cutting speed. For tool steel NC6, the values of cylindricality deviation remained constant. When analyzing the trend line generated for a sample made of aluminum alloy, we can see an increasing trend in deviation of cylindricality (see the green trend line in Fig. 13). Fig. 14 shows an example of the cylindricality profile obtained for a sample made of S355 steel, taking into account the following machining parameters: $f_{\mathrm{n}}=0.2 \mathrm{~mm}, v_{\mathrm{c}}=100 \mathrm{~m} / \mathrm{min}, a_{\mathrm{p}}=$ $0.15 \mathrm{~mm}$ (Tab. 5). We can see that the obtained cylindricality profile is characterized by a high irregularity, which also indicates the negative impact of too low cutting speeds on the condition of the machined surface.

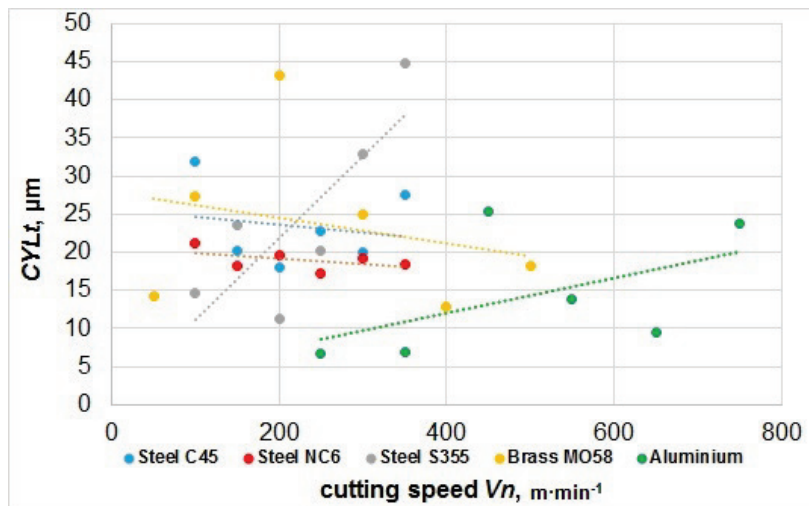

Figure 13 Graph showing dependency of the value of cylindricality deviation $C Y L t$ on the value of the cutting speed $v_{c}$

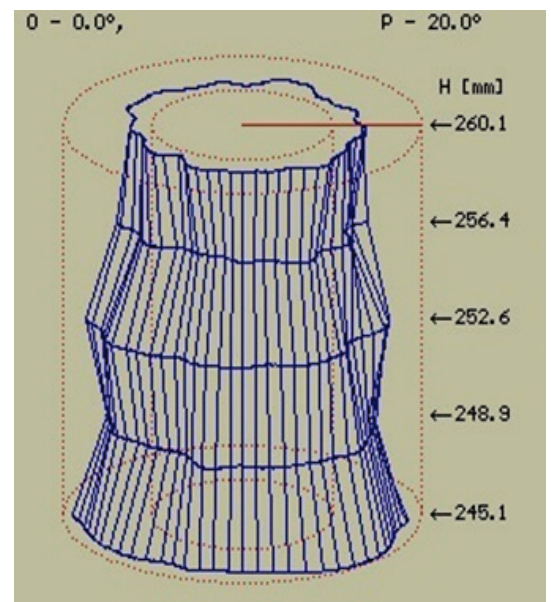

Figure 14 Graph showing dependency of the value of cylindricality deviation $C Y L t$ on the value of the cutting speed $v_{c}$

As in chapter 6.1, Pearson's linear correlation coefficients were calculated to quantify the effect of cutting speed on the values of roughness, roundness and cylindricality parameters. The results are presented in Tab. 7 .

Table 7 Values of Pearson's linear correlation coefficients $(r)$

\begin{tabular}{|c|c|c|c|c|}
\hline & $R_{\mathrm{a}}$ & $R_{\mathrm{t}}$ & $R O N t$ & $C Y L t$ \\
\hline C45 & -0.73 & -0.80 & -0.79 & -0.18 \\
\hline NC6 & 0.76 & -0.65 & -0.48 & -0.51 \\
\hline S355 & -0.65 & -0.75 & -0.80 & 0.81 \\
\hline MO58 & -0.42 & -0.69 & -0.67 & -0.26 \\
\hline AW-2017A & -0.67 & -0.72 & -0.30 & 0.52 \\
\hline
\end{tabular}

When analyzing the obtained Pearson's correlation coefficients, it can be concluded that the correlation between the analyzed parameters and the values of the cutting speed $v_{\mathrm{c}}$ are lower than in the case of the feed rate analysis $f_{\mathrm{n}}$ (see Tab. 6). For roughness parameters $R a$ and $R t$ there was a significant correlation. Considering the results of roundness deviation measurement, we can see that only for the sample made of aluminum there was a clear but small correlation between RONt and $v_{\mathrm{c}}$. For the rest of the examined materials there was a significant correlation. The smallest absolute values of Pearson's coefficients were obtained for CYLt cylindricality parameters and $v_{\mathrm{c}}$ cutting speed values. Relevant correlation significance was obtained only for S355 steel. Considering the results presented in Tab. 7, it can be concluded that in most cases negative values of Pearson's linear correlation coefficients were obtained. This means that an increase in the cutting speed $v_{\mathrm{c}}$ causes a decrease in the values of roughness, roundness and cylindricality parameters for most of the materials studied.

\subsection{Analysis of the Technological Heredity of the Turning Process}

Technological inheritance is defined as the phenomenon of transfer of specific properties of an object between successive technological processes of a given product. If these features remain in the final (finished) product, we talk about technological heredity. Technological heredity is particularly visible in the case of manufacturing precise elements using numerous technological procedures.

When analyzing the results of experimental studies presented in this article, it can be stated that the technological parameters of the longitudinal turning process significantly affect the condition of the machined surface, which is an example of technological heredity. Thanks to appropriately selected technological parameters of the longitudinal turning process it is possible to obtain the desired quality of the machined surface while maintaining satisfactory machining efficiency. Results of the studies showed that an increase in feed rate caused an increase in the values of roughness and cylindricality parameters with a simultaneous decrease in the deviation of roundness. Therefore, it can be concluded that the increase in feed rate causes deterioration of the quality of the machined surface. In case of identifying longitudinal turning operations as the final technological process of a given workpiece, which does not require further machining, it may result in excessive abrasive wear of the cooperating surfaces and reduce the service life of the made workpiece. On the other hand, excessive deviation of cylindricality and roundness in the case of elements 
performing rotary motion may cause additional vibrations and noise of machine parts, which is an unfavorable phenomenon. This is an example of the phenomenon of operational heredity, i.e. the effect of errors (inconsistencies) occurring during the technological process on the functional properties of the finished workpiece. It should be added that excessive values of deviations in roundness and cylindricality may have been inherited from previous technological operations, e.g. process of drawing or rolling of bars, rough turning of bars in order to prepare samples for testing. Hence, large deviations in roundness and cylindricality measured for different types of materials may result. Moreover, excessive values of roundness deviations, which resulted from previous technological processes, could influence the process of longitudinal turning, which was the subject of studies presented in the given article. These errors inheritably affect the process of longitudinal turning, which can cause generation of additional vibrations of the machine tool-tool-machined workpiece system, and this in turn further worsens the machined surface.

When analyzing the impact of the cutting speed on the condition of the machined surface, it can be generally stated that with its increase, the quality of the machined surface is improved. On the other hand, the values of deviations in roundness and cylindricality, similarly as during the feed analysis, were characterized by a large discrepancy. This is confirmed by the inheritance of technological errors from previous technological process operations.

In addition to the machining parameters, additional factors must be taken into account, which could inheritably affect the quality of the workpiece. These include incorrect fixing of the sample in a lathe chuck, which may have contributed to the formation of the so-called triangularity. The condition of the machine and the used cutting tools should also be taken into account. For example, the high susceptibility (low rigidity) of the machine tool and cutting tools may contribute to an increase in the roundness and waviness deviations, which is a hereditary factor.

Summarizing the analysis of the phenomenon of technological heredity of the longitudinal turning process, it can be stated that the machining parameters affect the condition of the machined surface, which then inheritively affects the quality of the final product. Moreover, errors resulting from improperly selected parameters of longitudinal turning may affect the quality of further machining operations, e.g. grinding. This may cause propagation of errors that have already occurred.

\section{CONCLUSIONS}

The main aim of the studies presented in this paper was to evaluate the influence of basic parameters of the longitudinal turning process such as feed rate $f_{\mathrm{n}}$ and cutting speed $v_{\mathrm{c}}$ on the quality of the machined surface. The basic parameters of roughness, as well as deviations of roundness and cylindricality of turned surfaces were studied. Additionally, the analysis of heredity of the longitudinal turning process was carried out. On the basis of the research work carried out, the following conclusions can be drawn:
1. The analysis of literature has shown that there is a lack of research work related to the comprehensive analysis of the influence of technological parameters of the longitudinal machining process on the condition of the machined surface. The majority of metrological studies is based on the analysis of the influence of machining parameters only on the values of the basic parameters of surface roughness. There are no detailed metrological studies related to the analysis of errors in the shape of turned surfaces, i.e. deviations in roundness and cylindricality. Moreover, there are no research works, where the technological heredity of the longitudinal turning process is evaluated.

2 . When analyzing the results of the roughness tests, it can be stated that the lowest value of the $R a$ roughness parameter was obtained for the sample made of aluminum AW-2017A, taking into account the lowest feed rate of $f_{\mathrm{n}}$ $=0.04 \mathrm{~mm}$. The obtained value of the roughness parameter equal to $R a=0.38 \mu \mathrm{m}$ corresponds to the roughness of the surface subjected to grinding machining. The highest roughness value was obtained for the sample made of C45 steel with the lowest machining speed $v_{\mathrm{c}}=100 \mathrm{~m} / \mathrm{min}$. Therefore, if the lowest surface roughness value (the lowest value of the $R_{\mathrm{a}}$ parameter) is essential for the design of the technological process of a given workpiece, then the lowest possible feed rates and high cutting speeds should be used.

3. When studying the roughness parameters describing the nature of surface irregularities, i.e. slope coefficient of the roughness profile $R_{\mathrm{ku}}$ and the asymmetry coefficient of roughness profile $R_{\mathrm{sk}}$, it can be stated that the roughness profiles measured for most samples are symmetrical in nature. In addition, a detailed analysis of these parameters showed that the surface roughness spikes were rounded. This was confirmed by measurements of surface topography (3D roughness). Such surfaces show a lower coefficient of friction, which is particularly important in the case of cooperating elements, because it extends the usable life of mechanisms.

4. When analyzing the influence of machining parameters of longitudinal turning on the values of the deviation of roundness and cylindricality, it can be stated that an increase in feed rate $f_{\mathrm{n}}$ causes a moderate decrease in the deviation of roundness of samples made of aluminum, bronze and S355 steel, while a moderate increase for samples made of C45 and NC6 steel. However, an increase in feed rate $f_{\mathrm{n}}$ causes an increase in the deviation of cylindricality CYLt for all analyzed materials. As the cylindricality allows for description of the shape of cylindrical parts in a more detailed way, it can be concluded that in order to obtain satisfactory deviation of the shape of cylindrical surfaces, small feed rates should be applied during longitudinal turning. In case of the analysis of the effect of the cutting speed $v_{\mathrm{c}}$ on the values of the deviations in roundness and cylindricality, no clear conclusions can be drawn. It should therefore be considered that the cutting speed has a negligible effect on the shape of cylindrical workpieces.

5. When looking at the overall results of the measurement of roundness and cylindricality deviations, it can be seen that there are large discrepancies between the deviations measured for different materials. This may be due to errors 
in previous technological processes, e.g. bar rolling or drawing, rough turning of bars.

6. To sum up the results of experimental studies, it can be concluded that the use of too low a feed rate is pointless, because it does not radically reduce roughness, but increases the value of deviations in roundness and cylindricality. In addition, low feed rates increase machining time. Cutting speed, on the other hand, should be relatively high.

7. Technological parameters of the longitudinal turning process influence the condition of the machined surface, which is an example of technological heredity. Excessive values of roughness, roundness and cylindricality influence further machining processes, which may cause new errors or increase the values of existing ones. In the case of identifying the longitudinal turning process as the final machining, then improperly selected machining parameters will affect the quality of the machined surface, and thus the operating properties of the finished product, e.g. generating additional vibrations, etc. This is an example of operational heredity. It should be added that deviations (errors) can be inherited from previous technological operations.

8. In addition to the machining parameters of the longitudinal turning process, many other factors influence the condition of the machined surface. These include, among other things, the irremovable part of the allowance, vibrations in the tool-machined workpiece system and partial wear of the cutting tool. The condition of the machine tool and the base material is also important. All these factors are the source of various errors, which, when combined, affect the condition of the final product. It is therefore necessary to detect and minimize errors at the various stages of the production process so that they are not inherited and do not affect the final product.

9. Based on the results of experimental studies, it should be stated that despite the optimal machining parameters (feed rate, cutting speed, depth of cut) specified by the cutting tools' manufacturers, the tools should be selected individually depending on the assumed expectations, e.g. high efficiency of the machining process, low roughness of the machined surface, etc.

The studies presented in this article are preliminary studies for a wider research work aimed at analyzing the phenomenon of technological heredity and operational heredity of selected technological processes. In further studies, the author will analyze the sources of errors in particular technological processes and assess how they affect the final product. In addition, a heredity factor will be developed to quantify the change in errors that occur as a result of individual technological processes.

\section{REFERENCES}

[1] Zmarzly, P., Adamczak, S., Kozior, T., \& Gogolewski, D. (2018). Surface Texture Quality of Models Manufactured by Additive Technology Fused Deposition Modeling", Proceedings of the 29th DAAAM International Symposium, pp.0853-0859, B. Katalinic (Ed.), Published by DAAAM International, ISBN 978-3-902734-20-4, ISSN 1726-9679, Vienna,Austria. https://doi.org/10.2507/29th.daaam.proceedings.123

[2] Savićević, S., Vukćević, M., Klimenko, S. A. \& Tanović, Lj. (2017). Impact of cutting elements on forces and roughness of surface during turning hard steel X160 CrMo V12 with CBN tool. Tehnički vjesnik, 24(4), 1001-1006. https://doi.org/10.17559/TV-20161013100743

[3] He, C. L., Zong, W. J., \& Zhang, J.J. (2018). Influencing factors and theoretical modeling methods of surface roughness in turning process: State-of-the-art. Int J Mach Tool Manu, 129, 15-26. https://doi.org/10.1016/j.jimachtools.2018.02.001

[4] Antić, A., Kozak, D., Kosec, B., Šimunović, G., Šarić, T., Kovačević, D. I,., \& Čep, R. (2013). Influence of tool wear on the mechanism of chips segmentation and tool vibration. Tehnički vjesnik, 20(1), 105-112. https://hrcak.srce.hr/97486

[5] Singaravel, B. \& Selvaraj, T. (2015). Optimization of machining parameters in turning operation using combined TOPSIS and AHP method. Tehnički vjesnik, 22(6), 14751480. https://doi.org/10.17559/TV-20140530140610

[6] Petrů, J., Zlámal, T., Čep, R., Sadílek, M. I., \& Stančeková, D. (2017). The effect of feed rate on durability and wear of exchangeable cutting inserts during cutting Ni-625. Tehnički vjesnik, 24(1), 1-6. https://doi.org/10.17559/TV-20131221170237

[7] Pawlus, P., Reizer, R., Łętocha, A., \& Wieczorowski M. (2019). Morphological filtration of two-process profiles. Bull. Pol. Ac.: Tech., 67(1), 107-113. https://DOI: 10.24425/bpas.2019.127339.

[8] Bartkowiak, T. \& Brown, C. A. (2019). Multiscale 3D Curvature Analysis of Processed Surface Textures of Aluminum Alloy 6061 T6. Materials (Basel, Switzerland), 12(2), 257. https://doi.org/10.3390/ma12020257

[9] Adamczak, S. \& Zmarzły, P. (2017). Influence of raceway waviness on the level of vibration in rolling-element bearings. Bull. Pol. Ac.: Tech., 65(4), 541-551. https://doi.org/10.1515/bpasts-2017-0059

[10] Nowakowski, Ł., Skrzyniarz, M., \& Miko, E., (2017). The assessment of the impact of the installation of cutting plates in the body of the cutter on the size of generated vibrations and the geometrical structure of the surface. Engineering Mechanics 2017, 734-737. Retrieved from http://www.engmech.cz/improc/2017/0734.pdf

[11] Prado, M. T., Pereira, A., Pérez, J. A., \& Mathia, T. G. (2017). Methodology for tool wear analysis by a simple procedure during milling of AISI H13 and its impact on surface morphology. Procedia Manufacturing, 13, 348-355. https://doi.org/10.1016/j.promfg.2017.09.090

[12] Oliaei, S. N. B. \& Karpat, Y. (2016). Investigating the influence of built-up edge on forces and surface roughness in micro scale orthogonal machining of titanium alloy Ti6Al4V. J. Mater. Process. Tech., 28-40. https://doi.org/10.1016/j.jmatprotec.2016.04.010

[13] Smolenicki, D., Boosa, J., Kuster, F., Roelofs, H., \& Wyen, C. F. (2014). In-process measurement of friction coefficient in orthogonal cutting. CIRP Annals, 63(1), 97-100. https://doi.org/10.1016/j.cirp.2014.03.083

[14] Ståhl, J-E., Schultheiss, F., \& Hägglund S. (2011). Analytical and Experimental Determination of the Ra Surface Roughness during Turning. Procedia Engineer, 19, 349-356. https://doi.org/10.1016/j.proeng.2011.11.124

[15] Qehaja, N., Jakupi, K., Bunjaku, A., Bruçi, M., \& Osmani, H. (2015). Effect of Machining Parameters and Machining Time on Surface Roughness in Dry Turning Process. Procedia Engineer, 100, 135-140. https://doi.org/10.1016/j.proeng.2015.01.351

[16] Adamczak, S., Zmarzły, P., \& Stępień, K. (2016). Identification and analysis of optimal method parameters of the V-block waviness measurements. Bull. Pol. Ac.: Tech., 64(2), 325-332. https://doi.org/10.1515/bpasts-2016-0037

[17] Dashchenko, A. I. (2013). Manufacturing Technologies for Machines of the Future 21st Century Technologies. Berlin: Springer Berlin. 
[18] Smirnov, G. V., Pronichev, N. D., \& Nekhoroshev, M. V. (2017). Effect of technological heredity on the fatigue strength in the manufacture of gas turbine engine blades. IOP Conference Series: Materials Science and Engineering, 177, 012130. https://doi.org/10.1088/1757-899X/177/1/012130

[19] Ljubimyj, N. S., Chepchurov, M. S., Chetverikov, B. S., Tabekina, N. A., \& Evtushenko, E. I. (2016). The technological heredity in the manufacture of the metallopolymeric build-forming molds. ARPN J EngApplScim, 11(20), 12302-12310.

[20] DIN EN 10083-3, Steels for quenching and tempering - Part 3: Technical delivery conditions for alloy steels.

[21] ISO 4957:2018, Tool steels.

[22] EN 10025 - Hot rolled products of structural steels.

[23] EN ISO 754-2, Aluminium and aluminium alloys - Cold drawn rod/bar and tube - Part 2: Mechanical properties.

[24] EN 12164:2016, Copper and copper alloys. Rod for free machining purposes

[25] Turning tools catalog 2017", accessed April 25, 2019 , Retrieved from https://www.sandvik.coromant.com/en$\mathrm{gb} /$ news/pages/main-catalogue-2017-released.aspx.

[26] Adamczak, S., Janecki, D., \& Stepien, K. (2011). Cylindricity measurement by the V-block method Theoretical and practical problems. Measurement, 44,164173. https://doi.org/10.1016/j.measurement.2010.09.039

[27] Grzesik, W. (2016). Prediction of the Functional Performance of Machined Components Based on Surface Topography. State of the Art, J Mater Eng Perform, 25(10), 4460-4468. https://doi.org/10.1007/s11665-016-2293-z

\section{Contact information:}

\section{Paweł ZMARZkY, PhD,}

(Corresponding author)

Kielce University of Technology,

Al. 1000-lecia P. P. 7, 25-314 Kielce, Poland

E-mail: pzmarzly@tu.kielce.pl 